\title{
Ultra-sonografia em uroginecologia
}

\author{
Ultrasonography in urogynecology
}

Manoel João Batista Castello Girão

Os exames de imagem foram empregados, durante muitos anos, na propedêutica da incontinência urinária, tendo como base os critérios de Green que, em 1962, descreveu uma classificação da incontinência urinária de esforço (IUE), baseada nos ângulos uretrovesical posterior (uretra e base de bexiga) e de inclinação uretral (eixo da uretra e perpendicular junto ao pube), aferidos na projeção lateral da uretrocistografia miccional com correntinha. Com o tempo, se percebeu que a medida desses ângulos era inútil para a caracterização do tipo de IUE, como também não servia para orientar a escolha da via de acesso para o tratamento cirúrgico, sendo gradativamente abandonada.

A ultra-sonografia do colo vesical foi, inicialmente, desenvolvida na tentativa de substituir a uretrocistografia com correntinha na propedêutica subsidiária da IUE, permitindo avaliar a mobilidade do colo vesical por meio de exame não invasivo e sem radiação. No entanto, foi também perdendo importância na medida em que a identificação da hipermobilidade do colo vesical ocupava papel secundário na programação terapêutica das pacientes com incontinência urinária de esforço. Sabe-se que há casos de incontinência de esforço sem hipermobilidade do colo vesical e de pacientes continentes com hipermobilidade.

Tal percepção foi acentuada com a descrição da teoria integral de Petrus e Ulmsten ${ }^{1}$, em 1990, na qual a explicação para a perda urinária se baseia na frouxidão dos ligamentos e da parede vaginal anterior, e não na topografia ou na hipermobilidade do colo vesical isoladamente.

Contudo, nos últimos anos, o interesse pela ultra-sonografia da uretra, do colo vesical e do assoalho pélvico vem aumentando significativamente. Fato facilmente comprovado pelo grande número de estudos recentemente publicados. Falta, no entanto, padronização adequada do exame, bem como delimitar com exatidão a sensibilidade e a especificidade desta avaliação no diagnóstico da incontinência urinária. No momento, não está claro qual o ganho oferecido por esse exame quando comparado a uma avaliação clínica cuidadosa e, muito menos, ao exame urodinâmico ${ }^{2,3}$.

Embora seja possivel avaliar o colo vesical e a bexiga por via abdominal, tem-se preferido as vias transperineal, translabial ${ }^{4,5}$ ou, como realizamos no Departamento de Ginecologia da Universidade Federal de São Paulo, subclitoridiana, por permitirem identificar, além do colo vesical, a uretra e a borda inferior da sínfise púbica com maior precisão.

Depreende-se da análise da literatura atual que há aspectos promissores do exame ultra-sonográfico a serem validados por meio de estudos prospectivos bem desenhados. Para tanto, deveremos ampliar os parâmetros passiveis de serem analisados por este método propedêutico, passando a estudar melhor a vascularização peri-uretral, as camadas musculares da uretra e do colo vesical, bem como os demais elementos do assoalho pélvico. Talvez isto se torne possivel com a ultra-sonografia tridimensional em tempo real associada à doplervelocimetria ou com o desenvolvimento de transdutores intra-uretrais de alta definição $0^{4,6,7}$.

Cumpre, contudo, mencionar que o enfoque atual da terapêutica da incontinência urinária de esforço não considera a mobilidade do colo vesical. Pouco muda, para o tratamento de uma paciente, sabermos se há ou não hipermobilidade; interessa muito mais o diagnóstico diferencial com a hiperatividade do detrusor e a identificação dos casos de defeito esfincteriano uretral, caso se programe o tratamento por técnica de colpofixação retropúbica.

Tendo em mente essas considerações, enfatizamos que, no momento atual, não se deve solicitar exames de ultra-som para o diagnóstico de incontinência urinária de esforço na prática clínica rotineira.

\footnotetext{
1 Livre-Docente do Departamento de Ginecologia da Universidade Federal de São Paulo - UNIFESP - São Paulo (SP), Brasil Correspondência: Manoel João Batista Castello Girão

Rua Borges Lagoa, 1065 - Conjunto 156 - Vila Clementino - 04038-032 - São Paulo-SP - Fone: (11) 5549-3864 
Devemos aguardar novas evidências, antes de propor qualquer modalidade terapêtica com base nos achados deste exame.

No resumo do estudo, apresentado nesta edição, o qual analisa o papel do ultra-som no diagnóstico da incontinência urinária e que nos foi enviado para considerações, não encontramos mencionado como critério de não inclusão a existência de defeito esfincteriano intrínseco da uretra, bem como não está assinalado o grau de enchimento vesical utilizado em todos os casos, fatos que podem interferir nos resultados. Contudo, os dados obtidos estão concordes com nossa atual posição quanto à aplicabilidade do exame de ultra-som para o diagnóstico da incontinência urinária.

Por fim, cumpre lembrar que a ultra-sonografia pode ser de grande valia na análise não invasiva do resíduo pós-miccional e das afecções do trato urinário superior. Assim, como pode identificar, muitas vezes de maneira fortuita, lesões vegetantes na superficie interna da bexiga.

\section{Referências}

1. Petrus PE, Ulmsten UI. An integral theory of female urinary incontinence. Experimental and clinical considerations. Acta Obstet Scand Suppl. 1990;153:7-31.

2. Dalpiaz O, Curti P. Role of perineal ultrasound in the evaluation of urinary stress incontinence and pelvic organ prolapse: a systematic review. Neurourol Urodyn. 2006;25(4):301-6.

3. Liang CC, Chang SD, Chang YL, Wei TY, Wu HM, Chao AS. Three-dimensional power Doppler measurement of perfusion of the periurethral tissue in incontinent women - a preliminary report. Acta Obstet Gynecol Scand. 2006;85(5):608-13.

4. Jimenez Cidre MA, Lopez-Fando L, Quicios Dorado C, de Castro Guerin C, Fraile Poblador A, Mayayo Dehesa T. Ultrasound for the diagnosis of female urinary incontinente. Arch Esp Urol. 2006;59(4):431-9.

5. Oliveira FR, Ramos JG, Martins-Costa S. Translabial ultrasonography in the assessment of urethral diameter and intrinsic urethral sphincter deficiency. J Ultrasound Med. 2006;25(9):1153-8.

6. Martin JL, Williams KS, Sutton AJ, Abrams KR, Assassa RP. Systematic review and meta-analysis of methods of diagnostic assessment for urinary incontinence. Neurourol Urodyn. 2006;25(7):674-83.

7. Cassado J, Pessarrodona A, Tulleuda R, Cabero L, Valls M, Quintana S, et al. Introital ultrasonography: a comparison of women with stress incontinence due to urethral hypermobility and continent women. BJU Int. 2006;98(4):822-8. 